\title{
Erratum regarding missing Declaration of Competing Interest statements in previously published articles
}

Declaration of Competing Interest statements were not included in published version of the following articles that appeared in previous issues of Clinical Epidemiology and Global Health. Hence, the authors of the below articles were contacted after publication to request a Declaration of Interest statement:

1. "Slippery slopes in public health practice" [Clinical Epidemiology and Global Health, 2021; 12 : 100904] DOI: https://doi.org/10 .1016/j.cegh.2021.100904

2. "Estimation of cardiovascular diseases (CVD) risk using WHO/ ISH risk prediction charts in tribal population of Chamarajanagar district, Karnataka" [Clinical Epidemiology and Global Health, 2020; 8 (4): 1217-1210] DOI: https://doi.org/10.1016/j.cegh.20 20.04.017

3. "Assessment of the occupational stress among nuclear medicine technical professionals in India" [Clinical Epidemiology and Global Health, 2021; 11: 100786] DOI: https://doi.org/10.1016 /j.cegh.2021.100786

4. "The Behavioral Model development of pregnant women in accordance to pregnancy treatment lifestyle" [Clinical Epidemiology and Global Health, 2021; 12: 100802] DOI: https://doi. org/10.1016/j.cegh.2021.100802

5. "Perception of earbuds side effects among teenager and adults in Eastern Province of Saudi Arabia: A cross sectional study" [Clinical Epidemiology and Global Health, 2021; 12: 100784] DOI: https://doi.org/10.1016/j.cegh.2021.100784

6. "The dynamics of inflammatory markers in coronavirus disease2019 (COVID-19) patients: A systematic review and meta-analysis" [Clinical Epidemiology and Global Health, 2021; 11: 100727] DOI: https://doi.org/10.1016/j.cegh.2021.100727

7. "Carotid artery stiffness measured by strain elastography ultrasound is a stroke risk factor" [Clinical Epidemiology and Global Health, 2021; 12: 100850] DOI: https://doi.org/10.1016/j.cegh .2021 .100850

8. "Prevalence of diarrhoea among under five children in India and its contextual determinants: A geo-spatial analysis" [Clinical
Epidemiology and Global Health, 2021; 12: 100813] DOI: htt ps://doi.org/10.1016/j.cegh.2021.100813

9. "Does cost of care influence the glycemic control, psychosocial illness and quality of care among adolescents with type 1 diabetes?: A hospital based cross section study in Mysuru, Karnataka" [Clinical Epidemiology and Global Health, 2020; 8 (3): 879-883] DOI: https://doi.org/10.1016/j.cegh.2020.02.016

10. "COVID-19 pandemic and psychological wellbeing among health care workers and general population: A systematic-review and meta-analysis of the current evidence from India" [Clinical Epidemiology and Global Health, 2021; 11: 100737] DOI: htt ps://doi.org/10.1016/j.cegh.2021.100737

11. "Depression and its associated factors among the older adults in rural, Tamilnadu, India" [Clinical Epidemiology and Global Health, 2021; 10: 100677] DOI: https://doi.org/10.1016/j.cegh .2020.100677

12. "Prevalence and determinants of the use of caesarean section (CS) in the dichotomy of 'public' and 'private' health facilities in West Bengal. India" [Clinical Epidemiology and Global Health, 2020; 8 (4): 1377-1383] DOI: https://doi.org/10.1016/j.cegh.2020.05.0 17

13. "Prevalence of oral mucosal lesions in nursing homes elderly people in western Iran" [Clinical Epidemiology and Global Health, 2021; 11: 100749] DOI: https://doi.org/10.1016/j.cegh .2021 .100749

14. "Effect of fenugreek on breast milk production and weight gain among Infants in the first week of life" [Clinical Epidemiology and Global Health, 2020; 8 (3): 656-660] DOI: https://doi. org/10.1016/j.cegh.2019.12.021

15. "Epidemiology and phylogenetic analysis of respiratory viruses from 2012 to 2015 - A sentinel surveillance report from union territory of Puducherry, India" [Clinical Epidemiology and Global Health, 2020; 8 (4): 1225-1235] DOI: https://doi.org/10 .1016/j.cegh.2020.04.019

DOIs of original article: https://doi.org/10.1016/j.cegh.2021.100802, https://doi.org/10.1016/j.cegh.2021.100904, https://doi.org/10.1016/j.cegh.2021. 100850, https://doi.org/10.1016/j.cegh.2020.04.019, https://doi.org/10.1016/j.cegh.2021.100813, https://doi.org/10.1016/j.cegh.2020.02.016, https://doi.org/ 10.1016/j.cegh.2020.100677, https://doi.org/10.1016/j.cegh.2019.12.021, https://doi.org/10.1016/j.cegh.2021.100786, https://doi.org/10.1016/j.cegh.2020.05. 017, https://doi.org/10.1016/j.cegh.2021.100749, https://doi.org/10.1016/j.cegh.2020.04.017, https://doi.org/10.1016/j.cegh.2021.100784, https://doi.org/10. 1016/j.cegh.2021.100727, https://doi.org/10.1016/j.cegh.2021.100737.

https://doi.org/10.1016/j.cegh.2022.100991

Available online 4 February 2022

2213-3984/C 2022 The Author(s). Published by Elsevier B.V. on behalf of INDIACLEN. All rights reserved. 